\title{
Transformando organizações públicas: a tecnologia da informação como fator propulsor de mudanças ${ }^{1}$
}

\section{Paulo Sérgio Vilches Fresneda}

\section{A necessidade de mudança}

A era da informação chegou provocando grandes mudanças nas organizações privadas, tais como: incríveis aumentos de produtividade, downsizing, reengenharia, formas criativas e diferenciadas de se fazer negócios, especialmente na área de serviços dirigida aos clientes, uso intensivo de tecnologia da informação (TI) e muitas outras mudanças significativas. Conseqüentemente estas organizações estão passando por um drástico e rápido processo de reorientação e reestruturação, tendo em vista que os modelos organizacionais existentes (idealizados há mais de 100 anos) se exauriram, não gerando respostas satisfatórias às necessidades e expectativas da sociedade moderna (leia-se clientes e competidores globais).

Como consequiência deste fato geral acima explicitado, novos modelos de organização estão surgindo, muitos dos quais estão transformando completamente a noção atual do que seja uma Corporação, uma Empresa, uma Instituição Pública, etc. Esta nova organização é voltada para atender às necessidades e expectativas dos clientes, com alta qualidade e produtividade, utilizando-se de uma estrutura organizacional leve, baseada em equipes de trabalho e processos de trabalho horizontais, com o mínimo de estrutura hierárquica, i.e., mínimo de camadas gerenciais ou níveis hierárquicos.

Dentre os insumos que tornaram possíveis esta mudança, está o uso intensivo do "recurso informação" e das tecnologias associadas à sua captação, armazenamento, tratamento e disseminação, chamadas de Tecnologias da Informação (TI). ${ }^{2}$ Tecnologias da Informação têm sido utilizadas intensamente por aquelas organizações que estão se

$\mathrm{PhD}$ em

Information Management, The George Washington University, Washington-DC, USA, Pesquisador da Secretaria de Administração Estratégica e da Empresa Brasileira de Pesquisa Agropecuária, Brasília-DF 
reestruturando no novo modelo e na nova forma de operação, impostos pelo mercado mundial altamente competitivo.

O setor público não poderia ficar impassível a essas mudanças, uma vez que a sociedade (leia-se contribuintes) está cada vez menos interessada em arcar com os custos de estruturas não-efetivas, ineficientes, ${ }^{3}$ as quais não provêem os produtos e serviços esperados pelos seus diversos segmentos. Somado a estes fatores, existe a necessidade de equilibrar o orçamento público, o que requer não só o repensar do papel do Estado, mas também a reestruturação e transformação das organizações públicas (OPs). Diante deste quadro, vários países iniciaram programas de reforma do Estado, tais como o National Performance Review nos EUA (National Performance Review, 1993) e o Programa de Reforma do aparelho do Estado (Câmara da Reforma do Estado, 1995) no Brasil, para citar alguns exemplos.

Desta forma há de se repensar ou, como afirmam certos especialistas da área, é preciso "reinventar" o setor público (OsBorne, 1992), propondo novos fins, formas de organização, estruturação e operação das instituições públicas com vistas ao atendimento das necessidades e expectativas da sociedade, cujos clientes são os cidadãos do país, contribuintes ou não.

Uma alternativa possível para a "reinvenção" de uma instituição pública pode ser viabilizada pelo tratamento organizado e sistemático e a utilização intensiva do recurso informação. A Tecnologia da Informação é o suporte para o uso efetivo e eficiente do recurso informação e, adicionalmente, pode ser utilizada com um fator decisivo na propulsão do processo de transformação de uma instituição pública.

A utilização adequada, organizada e oportuna de TI no processo de transformação de uma OP, requer o estabelecimento de um arcabouço metodológico para servir de guia geral desse processo de transformação, onde as mudanças organizacionais são projetadas e implementadas em perfeita harmonia com as TIs utilizadas como fator de propulsão e suporte a essas próprias mudanças.

\section{Premissas básicas do arcabouço metodológico}

A idéia básica deste trabalho é utilizar TI com um agente ativo no processo de transformação de uma organização pública e não utilizá-la para automatizar os processos existentes executados nas estruturas e arranjos organizacionais burocráticos atuais. Este último uso de TI tem sido, historicamente, o mais comum nas organizações públicas, o qual tem contribuído para fortalecer, ainda mais, a rigidez das estruturas organizacionais e os processos de trabalho existentes, i.e., o enfoque usual burocrático de 
operação de uma organização pública. Portanto, o objetivo deste trabalho é propor o uso de TI para quebrar a estrutura e cultura burocráticas, características comuns à maioria das organizações públicas, esperando transformá-las em organizações mais efetivas e eficientes.

$\mathrm{O}$ arcabouço metodológico proposto de uso de TI, no processo de transformação de organizações públicas, baseia-se principalmente nos seguintes pontos:

a) orientação para o cliente;

b) simplicidade;

c) foco em poucos alvos de mudança.

Para que um processo de transformação efetivo aconteça em uma organização pública, é imperativo que seus clientes (atuais e potenciais) sejam considerados os maiores interessados no mesmo. Isto significa que é necessário trazer para a área pública, com as devidas adaptações, as estratégias, métodos e processos similares àqueles utilizados por organizações privadas para ganhar e manter clientes satisfeitos com seus produtos e serviços.

É importante observar que um cliente de uma organização pública tem dois papéis, i.e., primeiro, ele é receptor dos produtos/serviços gerados pela organização (papel comum de um cliente de uma dada organização); segundo, de um cidadão, no qual ele está preocupado com a performance geral da organização, com o intuito de ter certeza de que o imposto pago está sendo utilizado apropriadamente. Uma discussão interessante sobre o papel e a relação entre clientes-cidadãos e as organizações públicas é apresentada por Henry Mintzberg (MinTZBerg, 1996, p. 76-78).

Finalmente, é também importante exercer pressão de mudança sobre a cultura burocrática arraigada, que quase não vê e serve pobremente os clientes da organização, no sentido de não colocar os clientes/cidadãos em frente aos assuntos internos da organização. Ações feitas nesta área certamente causarão mudanças de porte na organização, nos resultados, na estrutura, nos processos de trabalho e na cultura.

Outra característica deste arcabouço metodológico é a simplicidade. Esta característica é importante, porque para a sua disseminação e aplicação em várias organizações públicas será necessária uma explanação para outros agentes de mudança, que irão executar projetos similares de transformação de suas organizações. Quanto mais simples o arcabouço metodológico proposto, mais fácil será de ser entendido por terceiros, maior será sua atratividade para os executivos das OP's (facilita a venda política da mudança), e, menos complicado para implementar.

Como um corolário do princípio anterior (simplicidade), a proposta metodológica deve focar "poucos alvos de mudança", mas que sejam importantes e poderosos para quebrar a cultura e a estrutura burocrática de organizações públicas. Os dois alvos escolhidos que preenchem as 
condições anteriormente estabelecidas são os seguintes: Institutional Accountability ${ }^{4}$ e Equipes de Trabalho.

Institutional Accountability forçará uma organização pública a ser responsável pela produção de resultados vis-à-vis aos recursos (financeiros, humanos, materiais, informacionais, etc.) a ela alocados. Vários benefícios podem ser previstos, podendo ser citados os seguintes: aumento da responsabilidade dos executivos públicos; maior transparência das operações da organização; facilidade de auditoria por parte dos cidadãos; aumento da pressão por mudanças internas no intuito de obter melhor performance (ambas: efetividade e eficiência). Este alvo de mudança exercerá uma "pressão externa" na organização que acarretará subseqüentes mudanças internas.

Maiores detalhes sobre o conceito de accountability podem ser buscados nos artigos publicados por Anna M. Campos (CAmpos, 1990) e por Regina E. Herzlinger (HERZLINGER, 1996).

Equipes de Trabalho são uma força interna de pressão na forma de funcionar de uma organização pública. Considerando que, associado com as equipes de trabalho, andam lado a lado:

a) processos de trabalho interfuncionais (horizontais);

b) foco no cliente e nos resultados;

c) colaboração entre empregados, e

d) maior facilidade de auditoria do uso de recursos vis-à-vis aos resultados produzidos, elas podem provocar mudanças substanciais na estrutura e cultura burocrática de uma organização pública.

Finalizando essa seção, é apresentado um resumo dos principais direcionamentos utilizados na formulação do arcabouço metodológico proposto, quais sejam:

a) a cultura, missão, objetivos e metas, estrutura e processos de uma organização vêm em primeiro lugar quando se considera o uso de tecnologia da informação como insumo básico do processo de transformação da mesma. TI no contexto deste trabalho é considerada como uma ferramenta poderosa para o suporte do processo de mudança organizacional, mas primeiro, e sempre primeiro, devem vir as considerações organizacionais explicitadas anteriormente;

b) este trabalho resulta de pesquisa aplicada. Desta forma, o conteúdo aqui apresentado é proveniente de resultados de pesquisas sobre teorias, conceitos, enfoques, metodologias e experiências práticas documentadas na literatura e relacionadas com transformação de organizações, privadas e públicas;

c) considerando que a literatura é pródiga em material relacionado com a transformação de organizações privadas, foram utilizadas idéias e práticas empregadas por estas organizações, com as devidas adaptações para uma organização pública, e incorporadas no modelo proposto; 
d) as idéias contidas neste artigo foram organizadas de forma a facilitar o desenvolvimento futuro de material didático de suporte, no treinamento de técnicos do setor público, em como utilizar tecnologia da informação como um fator propulsor do processo de transformação de organizações públicas.

\section{O arcabouço metodológico proposto}

Na elaboração desta proposta metodológica, foram utilizados vários modelos descritos na literatura, muitos dos quais projetados para organizações privadas. Os dois mais utilizados neste trabalho foram: a) o Triângulo Estratégico e b) o modelo do "MIT - Massachussets Institute of Technology", modelos estes projetados para uso em organizações privadas. O primeiro foi criado pelo professor Richard E. Walton da University Harvard (WALton, 1993). O segundo foi o resultado de um projeto do MIT denominado "Programa de Pesquisa: a gerência nos anos 90" (ScotTMorTOn, 1991).

O estudo e a análise destes dois modelos, levadas em conta as devidas adaptações para aplicação em organizações públicas e respeitadas as premissas básicas fixadas, chegaram a uma proposta inicial do modelo, a qual foi aperfeiçoada através de discussões com profissionais de diversas organizações públicas federais brasileiras.

Os parágrafos a seguir apresentam uma visão geral do modelo proposto. O ponto de partida foi o cliente-cidadão da organização. A razão principal desta escolha é que o processo de mudança de uma organização pública será facilitado se existir uma pressão externa a ela, advinda de seus maiores interessados: seus clientes e dos cidadãos em geral.

Portanto, um cliente de uma OP tem uma relação direta com os produtos e serviços providos por ela e com sua responsabilidade como instituição pública. Relacionada com seu primeiro papel, um cliente está interessado em adquirir/receber produtos e serviços de qualidade, no tempo adequado e, em geral, pelo menor preço. No segundo papel, o de cidadão, os clientes estão preocupados com a performance global da OP, ou seja, com a eficiência e a efetividade da mesma. Esta performance global pode ser melhor traduzida e medida através de medidas de performance.

$\mathrm{O}$ acima colocado força uma OP a estabelecer uma visão corporativa e objetivos de longo prazo, os quais devem levar em conta os aspectos de institutional accountability (medidas de performance $\rightarrow$ perspectiva da sociedade). Ao lado disto, mecanismos têm de ser criados para conectar medidas de performance aos objetivos e metas corporativas. 
Ambos os caminhos, produtos e serviços de qualidade e responsabilidade com transparência, levam à necessidade de melhorar ou reengenheirar os processos de trabalho existentes ou a serem criados na organização, os quais são executados por equipes de trabalho. O recurso crítico que permite este arcabouço funcionar adequadamente e tornar sua implementação factível é a informação. Esta afirmação implica que a TI é a ferramenta fundamental no suporte das mudanças e na operação futura da organização transformada, uma vez que ela é a ferramenta que coleta, armazena, processa e distribui o recurso informação.

Ponto importante e crucial neste processo de mudança: nada acontecerá, a menos que os recursos humanos sejam tratados adequadamente no processo de mudança. Isto implica que todas as mudanças propostas e decorrentes do uso deste arcabouço metodológico devem ser adequadamente gerenciadas (Figura 1: caixa Gerência da Mudança) e sempre deve ser levado em conta o desenvolvimento dos recursos humanos dos vários tipos: gerencial, técnico e administrativo.

A Figura 1 mostra o arcabouço metodológico proposto:

\section{Figura 1: Arcabouço metodológico proposto ${ }^{5}$}

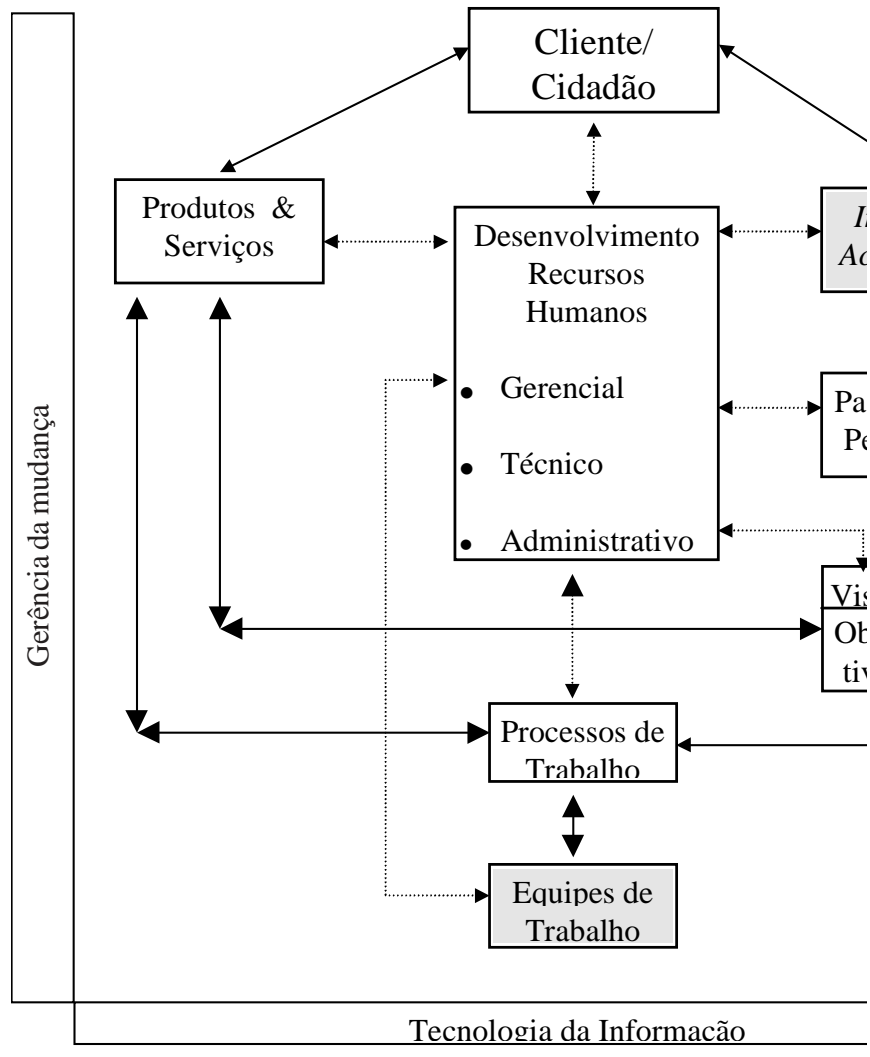


Como foi mencionado anteriormente neste artigo, os dois alvos principais de mudança são institutional accountability e equipes de trabalho. A Figura 1 mostra o relacionamento, ou melhor, o ponto de encontro sinérgico entre estes dois alvos, os "processos de trabalho", os quais geram os produtos e os serviços para os clientes, coletam e produzem as informações necessárias, as quais são agregadas e se transformam em medidas de performance organizacional, insumo básico para se auditar a institutional accountability.

É importante enfatizar que:

a) o uso deste arcabouço metodológico deve ser ajustado para cada $\mathrm{OP}$, levando-se em conta suas particularidades, cultura, considerações políticas e disponibilidade de recursos. Isto significa que para cada OP deve ser criada uma estratégia única, ou no mínimo ajustada, de aplicação desta proposta metodológica;

b) cada "caixa" da Figura 1 em si requerirá um trabalho futuro de detalhamento em termos dos seus "ques e comos", com a incorporação de metodologias específicas que tratam dos vários aspectos de modelagem organizacional. Por exemplo, na caixa - Clientes/Cidadão, deverão ser utilizadas metodologias que identifiquem o mercado de atuação da OP e sua segmentação.

Será apresentada, a seguir, uma breve descrição de cada uma das caixas componentes do arcabouço metodológico proposto:

Cliente/Cidadão: razão da existência da OP. Na concepção deste modelo, o cliente de uma OP tem papel duplo, como já destacamos.

$\mathrm{Na}$ definição da fatia de mercado a ser atendida (que em muitos casos pode ser qualquer cidadão do país, englobando assim toda a população do país), a OP deverá se valer de metodologias adequadas para identificar, segmentar, levantar necessidades e expectativas e avaliar o grau de satisfação com os produtos e serviços gerados pela OP.

Uma vez que o objetivo é a transformação de OPs, os estrategistas do processo de mudança não podem ignorar a análise deste componente pelo lado da oferta, ou seja, da disponibilização de inovações em produtos e, especialmente, em serviços, que não fazem parte do rol de necessidades e expectativas identificadas junto aos clientes da OP.

Institutional Accountability: esta caixa representa a força externa de mudança que será exercida na $\mathrm{OP}$, i.e, a pressão dos clientes-cidadãos, direta ou indireta, sobre as organizações componentes do aparelho do Estado por produção de resultados com o uso eficiente e efetivo dos recursos públicos. Um exemplo de implementação da responsabilidade com transparência é o contrato de gestão, instrumento de definição dos resultados a serem produzidos por uma organização (pública estatal ou pública privada), com seus respectivos níveis de performance, tendo em vista a alocação de recursos públicos na mesma. 
Parâmetros de performance: a institutional accountability de uma OP será medida através de indicadores de performance organizacionais, ou seja, medidores da eficiência e efetividade da OP na transformação dos recursos públicos alocados (humanos, informacionais, financeiros, materiais) em resultados de interesse da clientela da OP. Estes parâmetros de performance organizacional devem estar intimamente conectados à área estratégica da OP, traduzindo-se, em muitos casos, nas metas associadas aos objetivos corporativos da organização.

Visão, missão, objetivos, metas: esta caixa representa o grande componente de nível estratégico da OP. Aqui são estabelecidas a visão, a missão e os objetivos corporativos que visam indicar o norte da OP, a razão da sua existência e os caminhos a serem trilhados para a realização de sua visão e missão corporativas. Este componente deve refletir, o mais claro possível, por um lado, as necessidades e expectativas do clienteconsumidor em termos de produtos e serviços providos pela organização e, por outro lado, os indicadores de performance que medem o grau de institutional accountability da OP. Estes indicadores de performance podem ser traduzidos nas metas corporativas, item componente da estratégia corporativa da OP.

Processos de trabalho: a realização da visão e da missão e a consecução dos objetivos e metas corporativas dependerão da execução dos processos de trabalho na organização. Estes processos são um conjunto de atividades que visam produzir resultados com certo nível de performance para uma dada clientela. Como as atividades pertencem a várias unidades funcionais, estes processos também são chamados de processos horizontais de trabalho. Os produtos e serviços da OP são os resultados gerados por uma seqüência de processos de trabalho internos da organização. Desta forma, os processos de trabalho executam a conexão entre os planos estratégicos e os clientes da OP, através da geração dos produtos e serviços demandados e/ou ofertados aos clientes pela OP.

Neste modelo proposto, os processos de trabalho são o ponto de encontro entre a força externa de mudança, a institutional accountability, e a força interna de mudança, as equipes de trabalho.

Equipes de trabalho: os processos de trabalho são executados por pessoas componentes das equipes de trabalho. As equipes de trabalho formam a força interna de mudança dentro do arcabouço metodológico proposto.

É importante salientar que a idéia sobre equipes de trabalho inclui, entre outros fatores:

a) o comprometimento e a responsabilidade dos componentes da equipe com os resultados produzidos pelo processo de trabalho e com os seus clientes, quer sejam internos ou externos à OP; 
b) o trabalho conjunto dos componentes da equipe deve operar de forma sinérgica;

c) a complementaridade de habilidades entre os membros da equipe para melhor executar as atividades componentes do processo de trabalho;

d) os componentes de uma equipe têm não só responsabilidades individuais com relação às suas tarefas, mas também têm responsabilidade relativa à equipe como um todo. A descrição desses fatores acima visam diferenciar o conceito de equipe de trabalho do usual e corriqueiro grupo de trabalho, tão comum nas organizações públicas.

Em resumo, para se ter uma organização voltada para a produção de resultados com performance, é necessário que as pessoas trabalhem organizadas para tal. A organização das pessoas em equipes de trabalho, executando processos de trabalho, tem sido apontada na literatura com um dos ingredientes básicos de uma organização de alta performance (Pinchot, 1994; Robiins, 1996, p. 346-348).

Produtos \& serviços: como o próprio nome indica, esta caixa especifica os produtos e serviços demandados pelos clientes e/ou ofertados pela OP. São produzidos pelas equipes de trabalho que executam os processos de trabalho, de acordo com o que é preconizado na missão e objetivos corporativos da OP.

Desenvolvimento de recursos humanos: tudo o que acontece em uma organização é produzido pela ação dos recursos humanos existentes. No caso de uma transformação de uma organização, os recursos humanos desempenham um papel primordial, pois basicamente a organização irá mudar se, e somente se, as pessoas componentes da mesma mudarem.

Esta caixa visa enfatizar a posição central dos recursos humanos com relação a todos os outros componentes e na operacionalização deste modelo de mudança. As ações de desenvolvimento de pessoal, em todos os seus níveis - gerencial, técnico e administrativo — são de suma importância para a obtenção de resultados de alta performance e na minimização das resistências às mudanças.

Gerência da mudança: todo processo de transformação organizacional acarretará mudanças no nível individual e de grupos de empregados da organização. Essas mudanças podem provocar resistências às novas propostas de funcionamento da OP, podendo dificultar ou mesmo inviabilizar os projetos de mudança, independentemente da qualidade técnica intrínseca dos mesmos.

Para evitar estes problemas, ações devem ser tomadas antes, durante e depois do processo de mudança, no sentido de minimizar resistências, cooptar os que estão a favor e neutralizar os que se opõem radicalmente à mudança proposta. Estas ações, executadas de forma coordenada, formam um plano de mudanças, que deve ser gerenciado adequadamente. 
Tecnologia da informação: A TI é responsável pelo provimento das informações necessárias para operar o processo de transformação da OP, através do suporte à viabilização das forças interna e externa, assim como aos demais componentes do modelo proposto. Cabe ressaltar que em uma OP transformada, o papel das TIs será de vital importância para a sua operação e gerência. A seção a seguir apresenta mais detalhes do papel da TI no modelo proposto.

\section{O papel da Tecnologia da Informação}

Um dos insumos indispensáveis para a operacionalização das duas forças de mudança, i.e., institutional accountability e equipes de trabalho, é o recurso informação. Sem as informações que compõem os parâmetros de performance, os executivos da OP não saberão se a organização está seguindo o caminho correto e na velocidade adequada, dificultando sobremaneira ou mesmo inviabilizando a medição da quantidade/qualidade dos resultados planejados para aquela OP específica. Este fato dificultaria ou não possibilitaria aos cidadãos e/ou orgãos externos de controle avaliarem a institutional accountability da OP.

Uma das grandes revoluções que a TI provocou nas organizações modernas foi a possibilidade de se projetar e de se implantar novas formas de organização do trabalho e, principalmente, aquelas baseadas nos processos de trabalho horizontais executados pelas equipes de trabalho. A TI possibilita hoje que equipes operem com seus membros dispersos em locais geográficos distintos e em períodos de tempo distintos, disponibilizando as informações necessárias para a execução das atividades dos processos de trabalho, a tempo e a hora, para cada membro da equipe.

As informações de suporte à implantação destas duas forças de mudanças são disponibilizadas basicamente pelas tecnologias da informação a seguir: Sistema de Informação Executivo para a força externa Institutional Accountability e Groupware para a força interna — Equipes de Trabalho.

A Figura 2 incorpora estas duas tecnologias da informação, expandindo o arcabouço metodológico proposto. 
Figura 2: Arcabouço metodológico proposto e tecnologia da informação

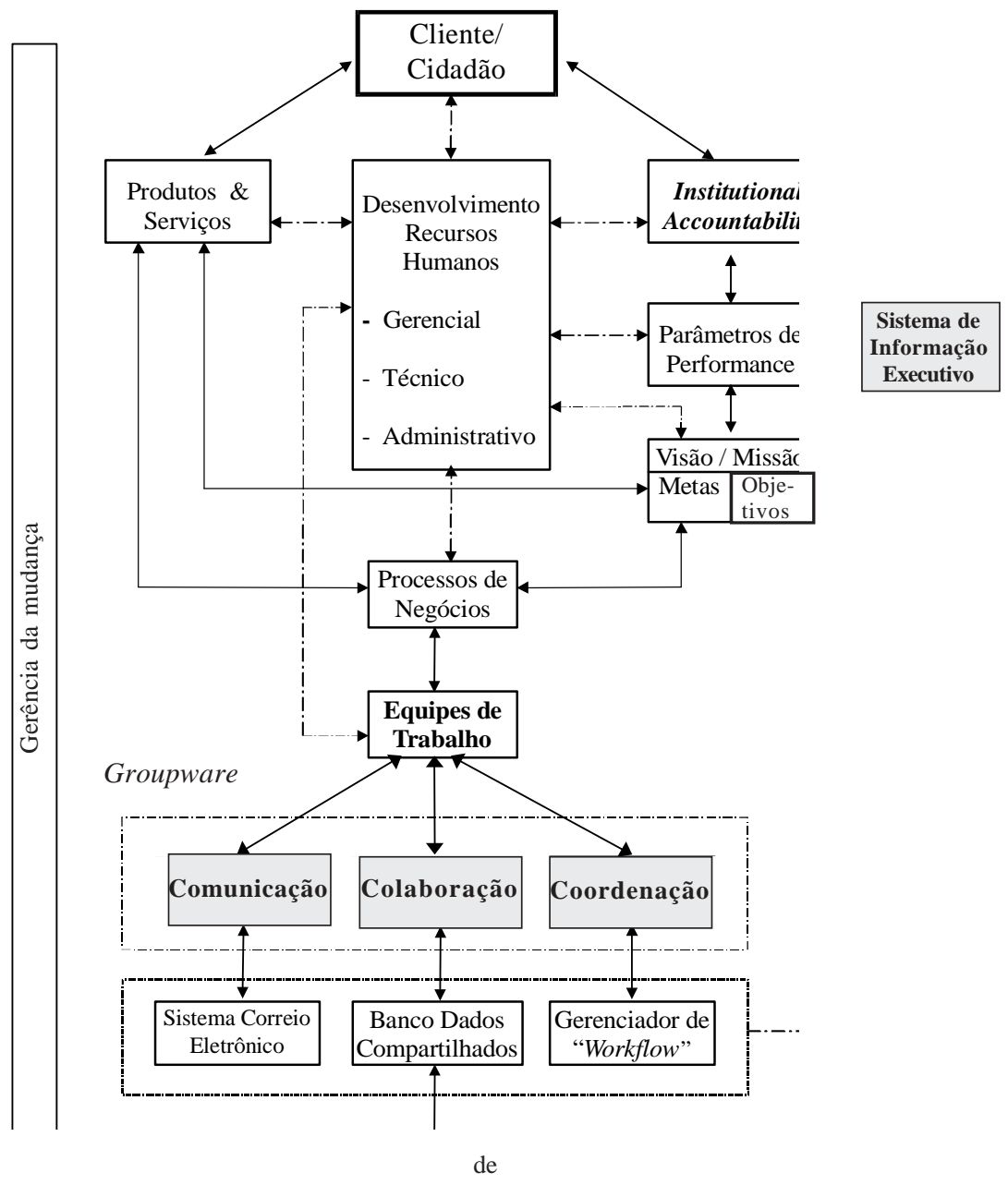

Segundo Steven Alter (Alter, 1992, p. 136), um sistema de informação executivo (SIE) é "um sistema altamente interativo que provê a executivos e gerentes acesso flexível às informações com a finalidade de monitorar resultados e condições gerais da organização". Desta forma, o papel do SIE no arcabouço metodológico proposto é o de um instrumento que capta dados internos e externos à organização pertinentes aos parâmetros de performance estabelecidos, organiza-os e os disponibiliza em forma de gráficos e tabelas aos executivos. Estas informações providas pelo SIE possibilitam aos executivos terem uma visão geral da direção e velocidade que a organização caminha no momento e de tomar decisões 
corretivas caso sejam necessárias. De acordo com a Figura 2, os bancos de dados dos SIE seriam abastecidos com dados provenientes dos bancos de dados mantidos pelos sistemas de informação corporativos (vendas, recursos humanos, financeiro, etc.) e complementados pelos dados gerados pelas TIs de suporte às equipes e processos de trabalho.

É importante ressaltar que o SIE deve ser estruturado com base na metodologia utilizada para definir e gerir os parâmetros de performance, que permitirão tanto ao gestor público quanto ao cidadão auferirem a efetividade e a eficiência da OP, e, por conseguinte, sua institutional accountability.

A tecnologia da informação de suporte às equipes de trabalho, Groupware, é a tecnologia que capacita grupos de pessoas a executarem atividades de comunicação, colaboração e coordenação. Estes três modos de trabalho, executados em conjunto ou em separado, ao mesmo tempo ou em tempos distintos, no mesmo local geográfico ou não, permitem que os resultados do trabalho em equipe sejam gerados (Lotus, 1995).

O modo de trabalho "comunicação" é responsável pelo fluxo de informação entre os componentes da equipe de trabalho, operando como um meio eletrônico passivo para a transmissão da informação. Como exemplo, pode ser citado um sistema de correio eletrônico.

Colaboração provê um espaço eletrônico compartilhado pelos membros de uma equipe para trocas de informação e discussões sobre os diversos assuntos de natureza semi-estruturada e pertinentes ao trabalho da equipe. Este espaço compartilhado é essencial para a gerência e minimização da ambigüidade inerente à interação entre seres humanos. Este modo de trabalho permite que os membros de uma equipe se reúnam virtualmente, minimizando assim a realização de reuniões face a face, com conseqüentes ganhos de produtividade e diminuição de custos operacionais. Bancos de dados compartilhados são utilizados para implementar o modo de trabalho colaboração.

Para as atividades mais estruturadas que são executadas pelos membros de uma equipe, o modo de trabalho coordenação provê o suporte adequado através da automação, do controle e do sincronismo da seqüência de execução das atividades de um processo de trabalho, baseado em regras e condições pré-estabelecidas. O modo coordenação é implementado pelas ferramentas de automação de fluxo de trabalho (workflow manager).

A Figura 2 traz ainda dois componentes de TI importantes para a operacionalização do modelo proposto: os "Sistemas de Informação" e a "Infra-estrutura de Processamento \& Transporte de Dados". O primeiro é formado pelo conjunto de sistemas de informação corporativos que em geral foram construídos para dar suporte informacional às grandes funções da organização, tais como: Recursos Humanos, Orçamento e Finanças, 
Contabilidade, Material, etc. Os bancos de dados mantidos por estes sistemas são uma fonte de dados para os SIE construírem e manterem atualizados seus bancos de dados sobre os indicadores de performance da organização. Outra ligação apresentada na Figura 2 é o fluxo de dados existente entre as ferramentas de Groupware e os Sistemas de Informação, através da qual as equipes de trabalho, de forma concorrente, utilizam-se de dados e fornecem dados aos Sistemas de Informação.

O segundo e último componente, a Infra-estrutura de Processamento \& Transporte de Dados, como o próprio nome diz, é composto por toda a infra-estrutura de hardware e software necessária para a coleta, processamento e transporte dos dados em uma organização. Esse componente se constitui no conjunto de computadores (de todos os portes), do software básico ( sistemas operacionais, utilitários diversos, etc..) e da rede de comunicação de dados que interliga esses vários computadores. Cabe ressaltar que em geral a grande parte dos investimentos em TI efetuado pela maioria das OPs realiza-se neste componente, ou seja, em ferramentas e infra-estrutura, quase sempre disconectados de planos de mudança e/ou melhoria organizacional. A conseqüência deste fato é o pequeno impacto que TI provoca no aumento da eficiência e efetividade da OP, uma vez que os gestores responsáveis pelos investimentos em TI estão mais preocupados em "informatizar" a organização do que tratar e gerenciar o recurso informação, este sim, um insumo vital na operação e na transformação das organizações.

Informação é o recurso vital para a viabilização de ambas as forças de mudança da organização indicadas no modelo proposto. As tecnologias da informação indicadas acima são os instrumentos de disponibilização deste recurso vital, a informação. Conseqüentemente, a utilização destas TIs, em perfeita harmonia com os demais componentes da proposta de mudanças de uma organização pública, operará como um fator propulsor destas mudanças.

\section{Considerações sobre a estratégia de implementação}

Considerando que a utilização deste arcabouço metodológico em uma organização pública irá provocar mudanças significativas e, conseqüentemente, resistências a este processo surgirão naturalmente, é importante discorrer sobre a estratégia de implantação com vistas a minimizar estas resistências e a aumentar a chance de sucesso do empreendimento.

Visando auxiliar os implementadores, o autor indica os seguintes tópicos relevantes, entre outros, a serem considerados no exercício do arcabouço metodológico proposto: 
- Envolvimento e comprometimento dos "donos do poder"

- Líderes x Gerentes

- Equipe técnica

- Implementação top-down x bottom-up

- Gerência de mudanças

\subsection{Envolvimento e comprometimento dos "donos do poder"}

Mudanças de porte em organizações não se iniciam e se processam com sucesso caso não haja envolvimento e o real comprometimento dos executivos da organização, isto é, dos detentores do poder posicionado no nível mais alto da organização. A aplicação deste arcabouço metodológico em um processo de transformação de uma OP, principalmente se é iniciado pela força externa, que trabalha com o componente estratégico da instituição, requer o aval e o apoio comprometido da alta direção da organização. Atualmente, este apoio da alta direção deverá ser facilitado pelos esforços da reforma do aparelho do Estado que estão pressionando os dirigentes de instituições públicas a trabalharem com o componente estratégico voltado para resultados e clientes. Uma fonte de pressão em nível estratégico é a formalização dos contratos de gestão entre os organismos controladores e a OP, nos quais são (ou deverão ser) estabelecidos os resultados e respectivos níveis de performance a serem obtidos pela OP vis-à-vis aos recursos públicos a ela alocados. Consequientemente, uma alternativa para cooptar e comprometer os executivos com a transformação de sua instituição, utilizando este arcabouço metodológico, é que o próprio se apresenta como uma alternativa para o provimento dos meios necessários para cumprir o contrato de gestão, firmado com orgãos superiores de controle, ao mesmo tempo que provê elementos para a transformação da OP.

\subsection{Líderes $x$ Gerentes}

A aplicação deste arcabouço metodológico provocará mudanças em uma OP, transformando seu formato organizacional, sua forma de funcionamento, sua forma de gestão e, conseqüentemente, sua cultura.

Para levar a cabo e com grandes chances de sucesso esse processo de transformação, é desejável a existência de liderança nos executivos responsáveis pelo processo de mudança. Este fato é importante por várias razões, entre as quais podem ser mencionadas:

a) a geração de uma visão futura da OP, e,

b) o maior envolvimento e comprometimento de todos na organização no processo de mudança, dada a credibilidade e a influência positiva do líder. 
O papel que a maioria dos executivos típicos de OPs desempenham é o de gerente, i.e., administradores do status quo existente, em geral preocupados com o cumprimento do ritual burocrático, e, quando muito, criando e implementando ações que provocam pequenas mudanças em detalhes operacionais da máquina burocrática. Para haver transformação real de uma OP, é necessária a criação de uma visão de futuro e para isso é desejável a existência do líder, que cria ou adota essa visão e conduz o processo de mudança.

Quando não existir nenhum executivo com o perfil de líder na organização, uma alternativa que pode ser utilizada é a elaboração da visão de futuro por um grupo de empregados, respeitados por sua competência técnica e conhecimento do negócio da OP, que seria posteriormente encampada pelos executivos que detêm o poder. Desta forma, um grupo formado por executivos e empregados formuladores da visão seria responsável pela implementação das ações de transformação, fazendo, assim, o papel do líder inexistente.

Em resumo, transformar uma OP requer uma visão de futuro da organização, que pode ser provida por um líder ou por um grupo de empregados que conheçam "a fundo" o "negócio" da OP. A implementação desta visão será facilitada com a presença do líder, conduzindo a organização (leia-se recursos humanos) do ponto A (status quo) ao ponto B (OP transformada). O arcabouço metodológico proposto provê uma estrutura de como o componente estratégico (visão, missão, objetivos corporativos, etc..) se relaciona com outros elementos importantes em um processo de transformação de uma organização.

\subsection{Equipe técnica}

Uma das chaves do sucesso no processo de transformação de uma OP é a formação de uma equipe que irá ser responsável pela implantação dos componentes do arcabouço metodológico proposto. Esta equipe deverá ser formada com os melhores e mais competentes empregados da OP, tendo em vista que um processo de transformação organizacional exige que os executores da mudança devam ter a competência e a habilidade para fazer a transição o mais suave possível e com poucos efeitos indesejáveis no ambiente e operação da organização, e, obviamente, minimizando, ao máximo, o risco de fracasso do projeto.

Esta equipe deve ser multidisciplinar, em geral envolvendo pessoas com as seguintes especialidades: área de negócios da OP, gerência de mudanças, desenvolvimento organizacional, tecnologia da informação e, possivelmente, um representante dos clientes da OP. Os membros da equipe deveriam ter uma dedicação mínima de $70 \%$ do tempo, sendo recomendável que o núcleo da equipe tenha dedicação integral. A equipe deve ser 
estruturada e gerenciada de forma a facilitar o uso efetivo do potencial humano existente, devendo se reportar diretamente à alta direção da OP.

Os membros desta equipe também seriam responsáveis por gerenciar e absorver know-how de consultores externos, que viessem a ser contratados para resolver problemas ou prover informações em áreas em que a OP não disponha de competência interna.

\subsection{Implementação top-down $\mathrm{x}$ bottom-up}

Do ponto de vista global de uma OP, o arcabouço metodológico pode ser implementado com um enfoque top-down (de cima para baixo, do geral para o detalhado) ou bottom-up (de baixo para cima, do detalhado para o geral). A relevância deste tópico deriva da necessidade de apresentar alternativas factíveis para aqueles que trabalham na área de desenvolvimento organizacional, no momento em que irão aplicar métodos e técnicas de transformação de uma OP, uma vez que as condições (sóciopolíticas, financeiras, recursos humanos, etc..) podem recomendar a utilização de um enfoque ou outro.

A implantação do arcabouço metodológico usando o enfoque top-down está relacionado à força externa - Institutional Accountability — e aos componentes estratégicos da OP (visão, missão, etc..). O uso deste enfoque requer o apoio e o comprometimento da alta direção da OP e, preferencialmente, de um líder entre os executivos desta OP, e, dado o seu escopo geral, por se tratar de toda a organização, pode levar mais tempo para produzir resultados com visibilidade imediata para todos. Por outro lado, este enfoque, por trabalhar do geral para o detalhado, prepara a base para a execução de todas as atividades de implantação dos demais componentes do arcabouço metodológico, de forma lógica e organizada. Por exemplo, uma vez definida a visão, a missão, os objetivos corporativos e seus parâmetros de performance, fica mais fácil identificar quais são os processos de trabalho críticos da OP.

Quando não houver condições para a aplicação do enfoque topdown, principalmente por não estar a alta direção sensibilizada com as mudanças propostas para a OP, pode-se trabalhar nos componentes do arcabouço metodológico relacionados à força interna, i.e., as equipes de trabalho. Equipes de trabalho são grupos de pessoas que executam os processos de trabalho que irão produzir, em última instância, os resultados demandados pelos clientes da OP. Portanto, o componente inicial a ser tratado são os processos de trabalho. Como não deve existir uma clara visão da $\mathrm{OP}$, os processos de trabalho críticos não poderão ser identificados a partir do enfoque top-down e terão de ser identificados com base na intuição e conhecimento do negócio da OP, constituindo-se, desta forma, em um enfoque bottom-up, de baixo para cima. O risco que se corre aqui é que uma vez que não se tem uma visão geral da organização, podem ser 
escolhidos processos de trabalho que não são críticos ao cumprimento da missão da $\mathrm{OP}$, ou mesmo nem deveriam ser executados no novo formato da OP transformada.

Visando facilitar o entendimento da aplicação dos dois enfoques de tratamento no processo de transformação de uma $\mathrm{OP}$, consideremos que o arcabouço metodológico seja um quebra-cabeças de 1.000 peças que forme a figura de um castelo. No enfoque top-down, estaria disponível uma foto do castelo ("o plano estratégico") e instruções de como dispor as peças. Já no enfoque bottom-up, não se sabe que a figura final da montagem será um castelo, e, no melhor dos casos, tem-se uma idéia difusa do castelo resultante. Isso leva a um processo de ajuste das peças na tentativa de montar o quebra-cabeças até chegar à figura final. Este processo pode levar a várias montagens e desmontagens do quebra-cabeças, o que embora produza resultados parciais e de curto prazo, no longo prazo custará caro e poderá não levar à montagem da figura completa do castelo.

\subsection{Gerência da mudança}

Transformar uma organização significa implementar mudanças profundas, muitas vezes radicais, sobre o status quo existente. No cerne das mudanças organizacionais está a mudança dos recursos humanos da organização. Qualquer processo de transformação, que não leve em consideração os recursos humanos envolvidos em primeiro lugar, tem grandes chances de fracassar.

A gestão de mudanças inclui a orquestração de um conjunto de atividades que objetivem a redução da resistência e aumente o comprometimento dos recursos humanos com o estado futuro desejado. Ela é importante e necessária para que as pessoas (“átomos” do processo de mudança) adotem os novos processos e tecnologias associadas de acordo com o planejado, de forma a realizar os benefícios esperados. Portanto: informar, envolver, convencer e comprometer os recursos humanos da organização, de forma a minimizar as barreiras humanas e organizacionais contra as mudanças que visam levar a OP ao estado futuro desejado, ou seja, a gestão da mudança, é um componente importantíssimo dentro da proposta.

Cabe primeiramente à equipe técnica a tarefa da gestão de mudanças, executada concorrentemente com as transformações técnicas propostas.

\section{Comentários finais}

Transformar organizações em geral, e as públicas em particular, é uma tarefa difícil, complexa, geradora de conflitos, que dispende recursos e que requer, no mínimo, o apoio dos detentores do poder e de um plano 
de mudanças, claro e explícito, para todos na organização. Este artigo objetivou apresentar algumas idéias sobre este plano de mudanças na forma de uma proposta de arcabouço metodológico, na qual a TI atua simultaneamente como componente de suporte e propulsor da mudança, e, de forma integrada, com os demais componentes do modelo.

Outra faceta desta proposta é o número mínimo de forças de transformação da OP. O objetivo é evitar a abertura de várias frentes de mudança de uma OP e suas desvantagens decorrentes devido às dificuldades de gestão e integração entre as várias ações de mudança. As duas forças consideradas no arcabouço são poderosas e complementares, atacando o problema da transformação da organização com pressões endógenas e exógenas, que sinergicamente se encontram nos processos de trabalho executados pela organização. Esta preocupação simplifica a proposta metodológica, facilita o seu entendimento e a sua implementação, tornando o arcabouço um roteiro geral do processo de transformação de uma OP. É importante frisar que este roteiro deverá sofrer ajustes e detalhamentos posteriores, à medida da implementação do mesmo e em função da cultura da organização, do contexto do processo de mudança, da competência disponível e dos recursos alocados.

Também foi levado em conta, na proposição do arcabouço metodológico, elementos relacionados com organização voltada para resultados, clientes e performance através dos componentes do modelo que implementam a força externa, ou seja, a institutional accountability. O objetivo foi, desta forma, de compatibilizar a proposta metodológica com os vários programas de reforma do setor público existentes atualmente em vários países, tais como o National Performance Review (National Performance Review, 1993) dos EUA e o Programa de Reforma do Aparelho do Estado (Câmara da Reforma do Estado, 1995) do Brasil, possibilitando, assim, que se cumpram os contratos de gestão ao mesmo tempo que se transformem as OPs em organizações para resultados e performance. 
1 Este trabalho é resultado do programa de pesquisa de pós-doutorado executado no Department of Engineering Management, da The George Washington University, Washington-DC, USA.

2 Tecnologia da Informação é entendida no contexto deste artigo como "um conjunto de equipamentos, programas, facilidades de comunicação, metodologias e demais meios utilizados para captar, tratar, armazenar, recuperar e distribuir o recurso informação.

3 Neste artigo o conceito de eficiência de uma organização pública está relacionado ao uso ótimo de recursos na geração de seus produtos e serviços. Já efetividade está relacionada com o nível de aceitação/satisfação dos produtos e serviços pelos clientes da organização pública.

${ }^{4}$ Esta palavra da língua inglesa não tem tradução precisa para o português. Anna M. Campos provê uma boa explicação sobre o conceito de accountability no artigo Accountability: quando poderemos traduzi-la para o português? (CAmpos, 1990). Neste documento, este termo será entendido como "responsabilidades institucionais com transparência", ou simplemente, "responsabilidades com transparência", i.e., os executivos públicos e suas OPs "respondem pelo" (são "accounted for") bom uso dos recursos públicos, produzindo resultados em nível de eficiência e efetividade compatíveis com as expectativas de seus cidadãos-clientes.

5 Observação: As setas pontilhadas indicam a dependência de todos os componentes do arcabouço metodológico proposto com o componente Recursos Humanos e seu desenvolvimento, sem o qual nada acontecerá na organização. 
ALter, S. Information Systems: a management perspective. The Benjamin / Cummings Publishing Co., Menlo Park, CA, 1992.

Bryson, J. M. Strategic Planning for Public and Nonprofit Organizations. Jossey-Bass Publishers, San Francisco, CA, 1995.

CÂmara da Reforma do Estado, Plano Diretor da Reforma do Aparelho do Estado. Presidência da República, Brasília, DF, 1995.

CAmpos, A. M., Accountability: quando poderemos traduzi-la para o português? Revista de Administração Pública (RAP), FGV, Rio de Janeiro, RJ, Fev/Abr 1990, p. 30-50.

Herzlinger, R. E., Can public trust in nonprofits and governments be restored? Harvard Business Review, Cambridge, MA, March-April 1996, p. 97-107.

Lotus Corp. Groupware: Communication, Collaboration and Coordination. Cambridge, MA, 1995.

MintzBerg, H. The Rise and Fall of Strategic Planning. The Free Press, New York, NY, 1994.

MintZBERG, H. Managing government: governing management. Harvard Business Review, Cambridge, MA, May-June 1996, p. 75-83.

National Performance Review. Creating a Government that Works Better \& Costs Less. Random House, Inc., New York, NY, 1993.

Osborne, D. \& Gaebler, T. Reinventando o Governo: Como o Espírito Empreendedor está Transformando o Setor Público. Editora MH Comunicação, Brasília, DF, 1992.

Pinchot, G. \& Pinchot, E. The End of Bureaucracy \& The Rise of the Intellingent Organization. Berret-Koehler Publishers, San Francisco, CA, 1994.

Robbins, S. P. Organizational Behavior. Prentice-Hall, Englewood-Cliffs, NJ, 1996.

Scott-Morton, M. S. Editor, The Corporation of the 1990's: Information Technology and Institutional Transformation. Oxford University Press, New York, NY, 1991.

Walton, R. E. Tecnologia da Informação: o uso de TI pelas empresas que obtêm vantagem competitiva. Editora Atlas, São Paulo, SP, 1993. 


\section{Transformando organizações públicas: a tecnologia da informação como fator propulsor de mudanças \\ Paulo Sérgio Vilches Fresneda}

A redefinição do papel do Estado na sociedade e a conseqüente transformação das Organizações Públicas (OPs) implementadoras deste novo papel têm sido tópicos-alvo constantes de discussão e ação de governos, tanto em países desenvolvidos, quanto nos em desenvolvimento.

Neste artigo é apresentada uma proposta metodológica para a transformação de OPs, utilizando-se de tecnologia da informação (TI) como fator propulsor deste processo de transformação. $\mathrm{O}$ arcabouço metodológico proposto está, basicamente, ancorado em duas forças de mudança: uma força externa à $\mathrm{OP}$ - Institutional Accountability, e uma força interna à OP - Equipes de Trabalho, que, sinergicamente, encontram-se nos processos de trabalho executados pela OP transformada. As TIs que viabilizam e provêem suporte à implementação das forças externa e interna são, respectivamente: Sistema de Informação Executivo e Groupware.

\section{Transformando organizaciones públicas: la tecnología de la información como factor propulsor de cambios}

\section{Paulo Sérgio Vilches Fresneda}

La redefinición del papel del Estado en la sociedad y la consecuente transformación de las Organizaciones Públicas (OPs) implementadoras de este nuevo papel han sido constantes tópicos-objeto de discusión y acción de gobiernos tanto en países desarollados como en aquellos en desarollo.

En este artículo se presenta una propuesta metodológica para la transformación de las OPs, utilizándose de tecnología de la información (TI) como factor propulsor de este proceso de transformación. La estructura metodológica propuesta está, basicamente, apoyada en dos fuerzas de cambio: una fuerza externa a la OP - Institutional Accountability - y una fuerza interna a la OP — Equipos de Trabajo — que, sinérgicamente, se encontran en los procesos de trabajo ejecutados por la OP transformada. Las TIs que viabilizan y proveen soporte a la implementación de las fuerzas externa e interna son respectivamente: Sistema de Información Executivo y Groupware.

\section{Transforming public organizations: using information technology as a change driver factor \\ Paulo Sérgio Vilches Fresneda}

The redefinition of State role in society and the consequent transformation of public organizations that will implement this new role have been target topics of government discussion and action, both in developed countries and in developing countries.

In this paper a methodological framework is presented for public organization transformation through the use of information technology as the driver factor of this change process. The proposed methodological framework is basically anchored in two change forces: an external force to the public organization - Institutional Accountability, and an internal force to the public organization - work teams, which sinergically, unite in the work processes carried out by the transformed public organization. The information technologies that make possible and support the implementation of the external and internal forces are, respectively: Executive Information System and Groupware.
Revista do

Serviço

Público

Ano 49

Número 1

Jan-Mar 1998

$\mathrm{PhD}$ em

Information

Management,

The George

Washington

University,

Washington-DC,

USA, Pesquisador

da Secretaria de

Administração

Estratégica e da

Empresa Brasi-

leira de Pesquisa

Agropecuária,

Brasília-DF 
